\title{
RESEARCH
}

Open Access

\section{Subjective social status and inequalities in depressive symptoms: a gender-specific decomposition analysis for South Africa}

\author{
Chipo Mutyambizi ${ }^{1 *} \mathbb{D}$, Frederik Booysen², Per Stornes $^{3}$ and Terje A. Eikemo ${ }^{3}$
}

\begin{abstract}
Background: Inequalities in mental health are a notable and well documented policy concern in many countries, including South Africa. Individuals' perception of their position in the social hierarchy is strongly and negatively related to their mental health, whilst the global burden of poor mental health is greater amongst women. This paper offers a first glimpse of the factors that shape gender-based health inequalities across subjective social status.

Methods: This study employs the cross-sectional 2014 South African Social Attitudes Survey (SASAS). The prevalence of depressive symptoms is measured with the aid of the CES-D 8-item scale, with analyses disaggregated by gender. Concentration indices $(\mathrm{Cl})$ are used to measure inequalities in depressive symptoms related to subjective social status. The study applies the Wagstaff decomposition to determine the factors that contribute to these gender-based inequalities.

Results: More than $26 \%$ of the study sample had depressive symptoms ( $95 \% \mathrm{Cl} 24.92-28.07$ ). The prevalence of depressive symptoms is significantly more pronounced in females $(28.46 \%$ versus $24.38 \% ; p=0.011)$. The concentration index for depressive symptoms is $-0.276(95 \% \mathrm{Cl}-0.341--0.211)$, showing large inequalities across subjective social status. The observed SSS-related inequality in depressive symptoms however is higher for males $(\mathrm{Cl}=-0.304)$ when compared to females $(\mathrm{Cl}=-0.240)(p=0.056)$. The most important contributor to SSS-related inequalities in depressive symptoms, at $61 \%$, is subjective social status itself (contributing $82 \%$ in females versus $44 \%$ in males). Other variables that make large contributions to the inequalities in depressive symptoms at $11 \%$ each are race (contributing $2 \%$ in females versus $25 \%$ in males) and childhood conflict (contributing $17 \%$ in females versus $4 \%$ in males).
\end{abstract}

Conclusion: Policy makers should target a reduction in the positive contribution of SSS to depression via the implementation of programmes that improve social welfare. Given the much greater contribution to inequalities among females, these policies should target women. Policies that protect children and especially the girl child from conflict can also be useful in reducing inequalities in depression related to subjective social status during adulthood. Overall, there is need for a multi-sectoral approach to address these inequalities.

Keywords: Subjective social status, Depression, Inequality, Concentration index, Gender, Decomposition analysis, South Africa

\footnotetext{
* Correspondence: CMutyambizi@hsrc.ac.za

${ }^{1}$ Research Use and Impact Assessment (RIA), Human Sciences Research

Council (HSRC), HSRC Building, 134 Pretorius Street, Pretoria 0002, South

Africa

Full list of author information is available at the end of the article
}

(c) The Author(s). 2019 Open Access This article is distributed under the terms of the Creative Commons Attribution 4.0 International License (http://creativecommons.org/licenses/by/4.0/), which permits unrestricted use, distribution, and reproduction in any medium, provided you give appropriate credit to the original author(s) and the source, provide a link to the Creative Commons license, and indicate if changes were made. The Creative Commons Public Domain Dedication waiver (http://creativecommons.org/publicdomain/zero/1.0/) applies to the data made available in this article, unless otherwise stated. 


\section{Background}

Research synthesis provides compelling evidence of the positive and reciprocal association between poor mental health and poverty or low socioeconomic status [1-3]. There is also robust empirical evidence from research synthesis that subjective social status (SSS), or one's perceived position in the social hierarchy, is strongly related to health, with low SSS being associated with poorer health outcomes [4-6]. This SSS gradient is particularly evident in the case of mental health [7-18]. The one explanation put forward for SSS being an important predictor of health outcomes is that it represents a cognitive average of multiple markers of socioeconomic status (SES) that accounts for past, current and future prospects and overall life chances $[7,19]$. The second explanation is that the SSS gradient embodies the hierarchy-health relationship, which hypothesises that relative social position has a direct and indirect impact on health. SSS has a direct effect on physiological processes and neuroanatomic structures, which enhances humans' biological vulnerability to disease. In addition, SSS indirectly affects health via an exposure to unhealthy behaviours [7]. Unlike OSS that mainly captures the mechanism of material deprivation, SSS also encapsulates the psychological mechanism of stress responsible for the socioeconomic health gradient [19]. Consequently, the SSS gradient in mental health generally persists when adjusting results for objective measures of socioeconomic status (OSS) such as education, occupation and income [7-11, 15-18].

The study of these SSS gradients in health with the aid of standard inequality indices such as the relative index of inequality (RII) [11-13] and the concentration index [20, 21 ] is limited to developed countries in Europe and the United Kingdom and United States. Furthermore, the predictors of SSS-related inequalities in health have not been investigated with the aid of decomposition analysis, which is important from a policy perspective insofar as it allows the identification of the factors driving these inequalities. Nor has such analysis been conducted from a genderbased perspective, which is necessary because the global burden of poor mental health is more pronounced in women [22-24]. In fact, gender-specific analysis on SSS and mental health has been restricted to developed countries contexts such as the United Kingdom [7, 14], Sweden [13] and Finland [18]. Such gender-specific analysis also meets the recent call for gender-based reporting in health inequality research [25]. Adverse childhood experiences, moreover, which are strongly associated with mental health in adulthood [26], has only been investigated in a single UK study on mental health and SSS [7] and then only childhood SES.

The inclusion in the nationally representative South African Social Attitudes Survey (SASAS) of the European Social Survey's (ESS) theoretically and methodologically grounded module on the social determinants of health [27], which includes information on childhood adversity of an economic and psychological nature, allows a first glimpse of the gender-specific factors that shape SSSrelated inequalities in mental health in a developing country context. The study's setting, moreover, is characterised by a high burden of depression [28-32], especially among women [30, 31, 33, 34], with depressive disorders being the fifth leading cause of years lived with disability by South Africans according to the 2017 Global Burden of Disease study [35]. South Africa is also characterised by high and rising social and economic inequality [36] that is the remnant of the colonial and apartheid systems' discriminatory policies and their influence on the country's social landscape and the population's psyche. Yet, only a single study has investigated the link between SSS and mental health in South Africa [34], but with a small purposive sample rather than a nationally representative survey. The questions posed in this paper are also important from a global policy perspective given the objectives of Sustainable Development Goals 3 and 10 to respectively reduce the burden of mental health and of inequalities by 2030 [37].

\section{Methods \\ Data}

The data used in the study originates from the nationally representative 2014 South African Social Attitudes Survey (SASAS), which fielded the survey module on social determinants of health in the European Social Survey (ESS7) in a developing country context [27]. This survey module on the social determinants of health has been extensively used to document health inequalities in European countries [38-40], including disparities in mental health [41-43], emphasising its suitability for this study. SASAS 2014 received ethical clearance from the HSRC and face-to-face interviews were conducted with a cross-sectional sample of 3108 consenting individuals aged 16 years and older. All study participants provided informed consent. The study used a two-stage stratified sampling design and the response rate was 89\% [44].

\section{Measures \\ Health outcomes}

The depression scale of the Centre for Epidemiologic Studies (CES-D) is widely used and has acceptable screening accuracy in general populations [45]. The 2014 SASAS adult questionnaire included the CES-D 8 variant of the scale, which contained a set of eight items that asked respondents if: they felt depressed, everything was an effort, sleep was restless, felt lonely, felt sad, could not get going, were happy or enjoyed life during the past week. Responses were none, some, most or all of the time, scored $0-3$. The CES-D 8 is a widely used and reliable measure of depression symptomology that has been applied both 
internationally and in South African studies [30, 41]. Previous studies have shown that the CES-D-8 scale is valid and reliable $[46,47]$. In terms of internal consistency, the Cronbach' alpha for the eight items in the scale is 0.773 . Approximately $96 \%$ of the study sample responded to all eight questions. Following Van dem Knesebeck et al. [48] and Huijts et al. [41], we created a 24 point scale from the individual responses to the eight questions [41]. Positive effect questions (such as happiness) were reverse scored. Mean imputation was applied where respondents had missing answers on 1 to 4 of the 8 questions (3.7\%). We then used the scale to create a dichotomous variable that took on the value of 0 when the scale had values 0 to 9 and 1 when the scale had values 10 to 24 [41, 48]. This outcome henceforth is referred to as 'depressive symptoms'.

\section{Subjective social status}

This study uses the measure of SSS to investigate the inequality in depressive symptoms. The construct validity of this scale is demonstrated by Cundiff et al. [49]. Similar to other studies $[4,7,13,14,50]$ and using a scale running from 1 (bottom) to 10 (top), individuals were asked to position themselves on this social hierarchy by the instruction: "In our society, there are groups which tend to be towards the top and groups which tend to be towards the bottom. Below is a scale that runs from the top (scoring 10 ) to the bottom (scoring 1 ). Where would you put yourself on this scale"? This variable was included in our study in two versions: one as a continuous variable for the construction of the $\mathrm{CI}$, using the original scoring, and one as a categorical variable for the subsequent decomposition of inequalities in the health outcomes. Values $1 \& 2=1$, $3 \& 4=2,5 \& 6=3,7 \& 8=4,9 \& 10=5$.

\section{Socio-demographic characteristics}

The socio-demographic variables included in our analysis are gender, race, age, marital status and place of residence. For accurate reporting and to emphasize the social and cultural differences between men and women we make use of the term gender instead of sex [51]. Gender was included as a binary variable: male $(=0)$ and female $(=1)$. Race was included as a categorical variable: African Coloured and Indian/Asian/White. Age was measured in years and included as a categorical variable with the following groups: $18-34$ years, 35-64 years, and $65+$ years. Marital status was included as a binary variable: married/civil partnership $(=0)$ and single $(=1)$. Place of residence was categorised as urban formal, urban informal, tribal, and rural formal.

\section{Other variables}

We also included a range of other socio-economic variables, measures of childhood adversity and lifestyle factors which influence health [52, 53]. The socio- economic variables included were employment status and education. Employment was coded in three categories: employed, non-labour force participant and unemployed. Education was coded in five categories of no education, primary, secondary, matric, and tertiary education.

Previous literature also reports that those who experience adverse childhood conditions are more likely to experience mental disorders $[26,54]$. Survey respondents were asked the following two questions regarding childhood adverse experiences: (1) Please tell me how often you and your family experienced severe financial difficulties when you were growing up? (2) Please tell me how often there was serious conflict between the people living in your household when you were growing up? Based on this detail, the childhood adversity variables included in our study are described as past childhood financial difficulties and past childhood conflict. Both were included as binary variables: hardly/never $($ no $=0)$ and always/sometimes (yes =1). In order to focus on the effects of these adversities during adulthood, respondents under 18 years were excluded from the analysis $(n=47)$.

Lifestyle factors included in the analysis comprise fruit consumption, vegetable consumption, physical activity, smoking, and alcohol consumption. Previous research indicates that healthier diets (more fruits and vegetables) are associated with better moods and less depression [55]. Fruit and vegetable consumption were both included as binary variables that took on the following values: 0 when consumed less than once a day over a week and 1 when consumed at least once a day. Respondents were asked how many of the last 7 days did they walk quickly, do sports or other physical activity for $30 \mathrm{~min}$ or longer. This was included as a binary variable; 0 - exercised up to 2 days a week and 1 - exercised at least 3 days a week. Respondents were also asked to describe their smoking behaviour. This was included as a binary variable with 0 less than daily/never and 1 - daily. Alcohol consumption was also included as a binary variable with 0 - less than or once a week/never and 1 - more than once a week.

\section{Measuring inequalities in depressive symptoms related to subjective social status}

Various measures have been proposed for measuring inequalities in health. Wagstaff et al. (1991) provides three basic criteria that an index of inequality in health needs to satisfy. These are (1) the measure should reflect the experiences of the entire population and not just the extreme ends (2) the measure should be sensitive to changes in the population in socioeconomic groups (3) the measure should reflect the socioeconomic elements to health inequalities [56]. The widely employed concentration index (CI) satisfies these minimum requirements [56] and is applied in this paper as a measure of inequality. 
The companion concentration curve (CC) plots the cumulative percentage of depressive symptoms on the vertical axis against the cumulative percentage of the sample ranked by SSS starting with those who reported lowest SSS and ending with those who reported higher SSS on the horizontal axis [57]. If everyone had the same depressive symptoms irrespective of their SSS then the $\mathrm{CC}$ would like on the 45-degree line, also known as the line of equality. If the depressive symptoms are more concentrated amongst those with low (high) SSS the curve lies above (below) the 45-degree line [57].

The $\mathrm{CI}$ is derived from the concentration curve $(\mathrm{CC})$ and lies between the values of -1 and +1 [57]. The index takes on a value of zero if there are no inequalities in the outcome variable (in this case depressive symptoms) and takes on negative values if depressive symptoms are more concentrated amongst those of low social status and positive values if depressive symptoms are concentrated amongst those of high social status [57]. The CI can then be measured as twice the covariance of the health variable and the ranking of the living standards variable $r$ (in this case SSS), divided by the mean of the health measure $(\mu)$ :

$$
C I=\frac{2}{\mu} \operatorname{cov}(h, r)
$$

Since the depressive symptoms variable in our study is binary we also make use of the Erreygers corrected concentration index which is algebraically expressed as shown below [58].

$$
E(h)=8 \operatorname{cov}\left(h_{i}, R_{i}\right)
$$

Our study makes use of the conindex command in STATA to estimate SSS-related inequalities in depressive symptoms [59].

\section{Decomposition of the $\mathrm{Cl}$}

The CIs for depressive symptoms can be decomposed to show the contributions of individual factors to SSSrelated inequalities. Our study makes use of the method proposed by Wagstaff et al. [60], which uses the following linear equation.

$$
h_{i}=\alpha+\sum_{j=1}^{q} \beta_{j} x_{i j}+\varepsilon_{i}
$$

Where $h$ is the health variable of individual $i, \alpha$ is the constant, $\mathrm{x}$ is a set of variables such as demographic and socio economic factors, $\varepsilon$ is the error term. If we have such linear model as shown in eq. (3), Wagstaff et al. shows that the concentration index for $h_{I}$ can be written as [60]:

$$
C I(h)=\sum_{j=1}^{q} \frac{\beta_{j} \overline{x_{j}}}{\mu_{h}} C I\left(x_{j}\right)+\frac{G C_{\varepsilon}}{\mu_{h}}
$$

This equation allows us to calculate the contribution of each factor to SSS-related inequalities in depressive symptoms. Since we applied the Erreygers normalisation to the calculation of the CI for the SSS-related inequalities in depressive symptoms, the corrected $\mathrm{CI}$ for the depressive symptoms variable is formulated as:

$$
E(h)=4 \sum_{j=1}^{q} \beta_{j} \overline{x_{j}} C I\left(x_{j}\right)+4 G C_{\varepsilon}
$$

Since the Generalised Linear Models (GLM) (with binomial family and identity link) is reported to be the best choice when decomposing inequality in a binary variable [61], eq. (5) is estimated using GLM and used to decompose SSS-related inequalities in depressive symptoms.

The contribution made by each factor is dependent on the sign and size of the calculated elasticity and CI for each regressor. If the contribution of variable $X$ is positive, then inequality in depressive symptoms would decrease if variable $X$ becomes equally distributed across the social group, ceteris paribus. The opposite is also true, i.e. if a factor's contribution is negative, the absence of inequalities in that variable would result in an increase in inequality, ceteris paribus. We also apply a bootstrapping method using 500 replications to estimate standard errors for the absolute contributions.

Statistical analysis was performed in STATA software version 13. Our data was weighted with post-stratification weights in order to account for clustering and survey design effects. The analysis reported here was restricted to individuals above the age of 18 years and those with nonmissing information on subjective social status. Among the cross-sectional sample of 3108 consenting individuals aged 16 years and older, 47 were below the age of 18 and were excluded. A further 34 had missing information on subjective social status and were also excluded. Our final analytic sample was 3027 .

\section{Results}

\section{Descriptive statistics}

Table 1 shows the study population's characteristics. About half of the respondents were male (48\%) whilst $52 \%$ were female. Most of the participants were African (78\%), between the ages of 18 to 34 years (49\%), single (60\%), and resided in formal urban settlements $(67 \%)$. The overall mean of the CES-D 8 scale was 7.39 (SD 4), whilst the CES-D 8 score for females (7.72) was statistically significantly larger than for males (7.04) $(p<$ 0.001 ). Approximately $26 \%$ of the population had depressive symptoms that could be indicative of clinical 
depression. The prevalence of depressive symptoms was statistically significantly higher amongst women $(28.46 \%)$ than men $(24.38 \%)(p=0.011)$.

More than $70 \%$ of adult respondents reported experiencing financial difficulties during childhood and 46\% reported experiencing childhood conflict. Most of the participants were unemployed (42\%) and had some secondary education (38\%). With regards to lifestyle factors, approximately half of the participants consumed fruits less than once a day (51\%), vegetables more than once a day (57\%), exercised 0-2 times a week (52\%), and never smoked or did not smoke daily (80\%). Self-reported alcohol consumption was low. The majority of respondents never consumed alcohol or consumed it less than once a week (93\%).

\section{Distribution of depressive symptoms by subjective social status}

Figure 1 shows the prevalence of depressive symptoms by SSS and gender. The prevalence of depressive symptoms is highest in the lowest quintile, at $45 \%$. The fourth quintile recorded the lowest prevalence of depressive symptoms, at $10 \%$, before increasing slightly to $15 \%$ in the fifth quintile. Generally, there is a statistically significant relationship between the prevalence of depressive symptoms and SSS, for both men and women and on aggregate $(p<0.001)$. In all quintiles other than quintiles 1 and 5, the prevalence of depressive symptoms is highest among females when compared to males.

\section{Concentration curves and indices for depressive symptoms}

Figures 2, 3 and 4 show the CC for the SSS-related inequalities in overall depressive symptoms, depressive symptoms amongst males and depressive symptoms amongst females, respectively. In all three instances, the curve lies above the 45-degree line of equality, showing that depressive symptoms are more concentrated amongst those with low SSS. All the CI are statistically significant and favour those with higher SSS for both males and females (i.e. ill health is concentrated among those of lower social status), as indicated by all curves lying above the line of equality. The observed SSS-related inequality in depressive symptoms is higher for males $(\mathrm{CI}=-0.304)$ when compared to females $(\mathrm{CI}=-0.240)$. This indicates that there is more inequality in the distribution of depressive symptoms among males when compared to females. The difference, however, is only weakly significant in statistical terms $(p=0.056)$

\section{Decomposition of SSS-related inequalities in depressive symptoms}

Results from the decomposition by gender are shown in Table 2. The first two columns show the elasticities
Table 1 Summary statistics, by gender

\begin{tabular}{|c|c|c|c|}
\hline Variable & Male & Female & Total \\
\hline \multicolumn{4}{|l|}{ CES-D 8 scale } \\
\hline Mean & 7.04 & 7.72 & 7.39 \\
\hline Standard deviation (SD) & 4.09 & 4.00 & 4.06 \\
\hline Median & 7.00 & 7.16 & 7.00 \\
\hline P25 & 4.00 & 5.00 & 5.00 \\
\hline P75 & 9.00 & 10.00 & 10.00 \\
\hline Depressive symptoms (\%) & 24.38 & 28.46 & 26.49 \\
\hline \multicolumn{4}{|l|}{ Gender } \\
\hline Male & & & 48.32 \\
\hline Female & & & 51.68 \\
\hline \multicolumn{4}{|l|}{ Race } \\
\hline African & 77.24 & 78.79 & 78.04 \\
\hline Coloured & 9.34 & 9.22 & 9.28 \\
\hline Indian/Asian/White & 13.42 & 12.00 & 12.68 \\
\hline \multicolumn{4}{|l|}{ Age } \\
\hline 18 to34 & 52.04 & 46.30 & 49.07 \\
\hline 35 to64 & 38.57 & 45.63 & 42.22 \\
\hline 65 plus & 9.39 & 8.07 & 8.71 \\
\hline \multicolumn{4}{|l|}{ Marital status } \\
\hline Married & 41.68 & 38.93 & 40.25 \\
\hline Single & 58.32 & 61.07 & 59.75 \\
\hline \multicolumn{4}{|l|}{ Place of residence } \\
\hline Urban formal & 64.54 & 68.69 & 66.69 \\
\hline Urban informal & 7.79 & 6.44 & 7.09 \\
\hline Tribal & 23.51 & 21.91 & 22.69 \\
\hline Rural & 4.16 & 2.96 & 3.54 \\
\hline \multicolumn{4}{|l|}{ Subjective social status } \\
\hline Mean & 4.56 & 4.14 & 4.35 \\
\hline S.D & 2.12 & 2.06 & 2.10 \\
\hline Quintile 1 (rank 1-2) & 21.56 & 27.19 & 24.47 \\
\hline Quintile 2 (rank 3-4) & 24.62 & 27.01 & 25.86 \\
\hline Quintile 3 (rank 5-6) & 36.49 & 33.52 & 34.96 \\
\hline Quintile 4 (rank 7-8) & 13.88 & 10.13 & 11.94 \\
\hline Quintile 5 (rank 9-10) & 3.44 & 2.15 & 2.77 \\
\hline \multicolumn{4}{|l|}{ Financial difficulties } \\
\hline Hardly/Never & 29.09 & 26.37 & 27.69 \\
\hline Always/Sometimes & 70.91 & 73.63 & 72.31 \\
\hline \multicolumn{4}{|l|}{ Childhood conflict } \\
\hline Hardly/Never & 54.19 & 54.57 & 54.39 \\
\hline Always/Sometimes & 45.81 & 45.43 & 45.61 \\
\hline \multicolumn{4}{|l|}{ Employment } \\
\hline Employed & 42.33 & 25.73 & 33.70 \\
\hline Non labour force participant & 20.01 & 29.18 & 24.78 \\
\hline Unemployed & 37.66 & 45.09 & 41.53 \\
\hline
\end{tabular}


Table 1 Summary statistics, by gender (Continued)

\begin{tabular}{|c|c|c|c|}
\hline Variable & Male & Female & Total \\
\hline \multicolumn{4}{|l|}{ Education } \\
\hline None & 2.82 & 4.35 & 3.61 \\
\hline Primary & 11.39 & 13.49 & 12.48 \\
\hline Secondary & 38.42 & 37.17 & 37.77 \\
\hline Matric & 36.31 & 35.42 & 35.85 \\
\hline Tertiary & 11.07 & 9.57 & 10.30 \\
\hline \multicolumn{4}{|l|}{ Fruits } \\
\hline$<$ once a day & 49.64 & 51.71 & 50.71 \\
\hline$>=$ once a day & 50.36 & 48.29 & 49.29 \\
\hline \multicolumn{4}{|l|}{ Vegetables } \\
\hline$<$ once a day & 43.48 & 42.54 & 42.99 \\
\hline$>=$ once $a$ day & 56.52 & 57.46 & 57.01 \\
\hline \multicolumn{4}{|l|}{ Physical activity } \\
\hline $0-2$ times & 44.11 & 59.12 & 51.75 \\
\hline 3-7 times & 55.89 & 40.88 & 48.25 \\
\hline \multicolumn{4}{|l|}{ Smoking } \\
\hline Less than daily/never & 68.37 & 91.24 & 80.19 \\
\hline Daily & 31.63 & 8.76 & 19.81 \\
\hline \multicolumn{4}{|l|}{ Alcohol } \\
\hline$<=$ once a week/never & 90.07 & 95.40 & 92.82 \\
\hline > once a week & 9.93 & 4.60 & 7.18 \\
\hline
\end{tabular}

and $\mathrm{CI}$ for each explanatory variable. The rest of the columns show the absolute contributions, their bootstrapped standard errors, the relative percentage contributions and the total percentage contributions of each explanatory variable to SSS-related inequalities in depressive symptoms.

As the table also shows, SSS makes the largest contributions to SSS-related inequalities in depressive symptoms
(61\%). This means that SSS-related inequalities in depressive symptoms would decrease by over $61 \%$ if there were no inequalities in SSS. It is notable that the contribution made by SSS to inequalities in depressive symptoms is much higher for females compared to males, $82 \%$ versus $44 \%$. Other factors that make significant contributions to SSS-related inequalities in depressive symptoms are race and past childhood conflict. In the decomposition analyses, race makes the larger contribution to SSS-related inequalities in depressive symptoms for males compared to females (26\% versus $2 \%)$. In contrast, past childhood conflict makes the larger contributions to SSS-related inequalities in depressive symptoms for females when compared to males (17\% versus $4 \%$ ). This means that SSS-related inequalities in depressive symptoms amongst females (males) would decrease by 17\% (4\%) if there were no inequalities in childhood adversity. In statistical terms, the other variables contribute only marginally to SSS-related inequalities in depressive symptoms. The lifestyle factors in particular make a relatively small contribution to SSS-related inequalities in depressive symptoms compared to other variables. The factors included in our study explained 97\% (or 0.269) of the overall SSS-related inequality in the prevalence of depressive symptoms.

From the table we can also see that residing in informal urban settlements, having experienced financial difficulties or household conflict during childhood, being unemployed, and consuming alcohol more than once per week is more concentrated amongst people of low SSS as indicated by the negative CIs. In contrast, having a tertiary education, consuming fruits and vegetables more than once a day, and exercising more often, as expected is more concentrated amongst those of high SSS, as shown by the positive CIs.

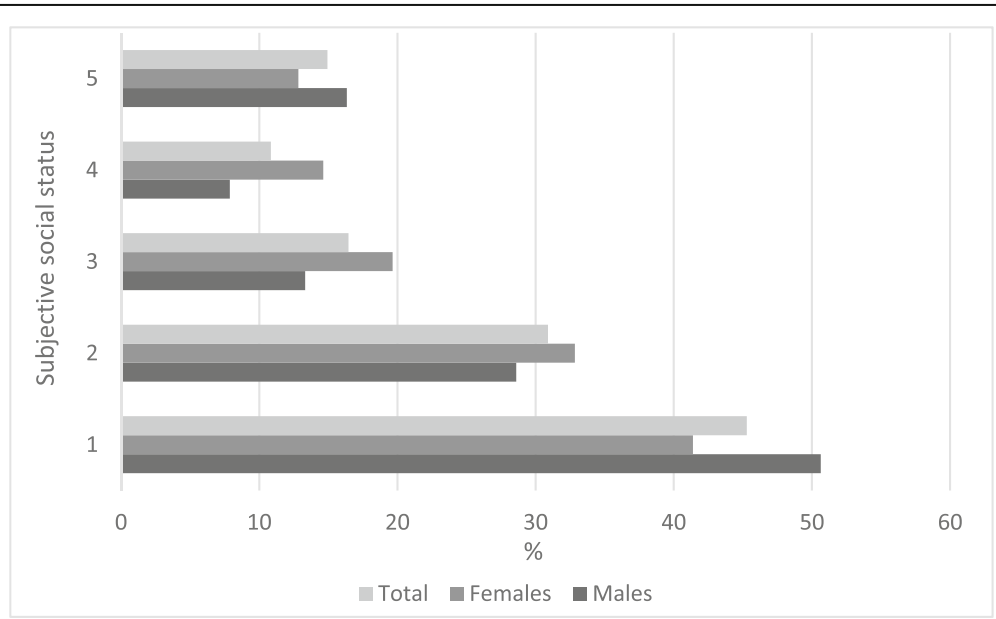

Fig. 1 Prevalence of depressive symptoms, by subjective social status and gender 


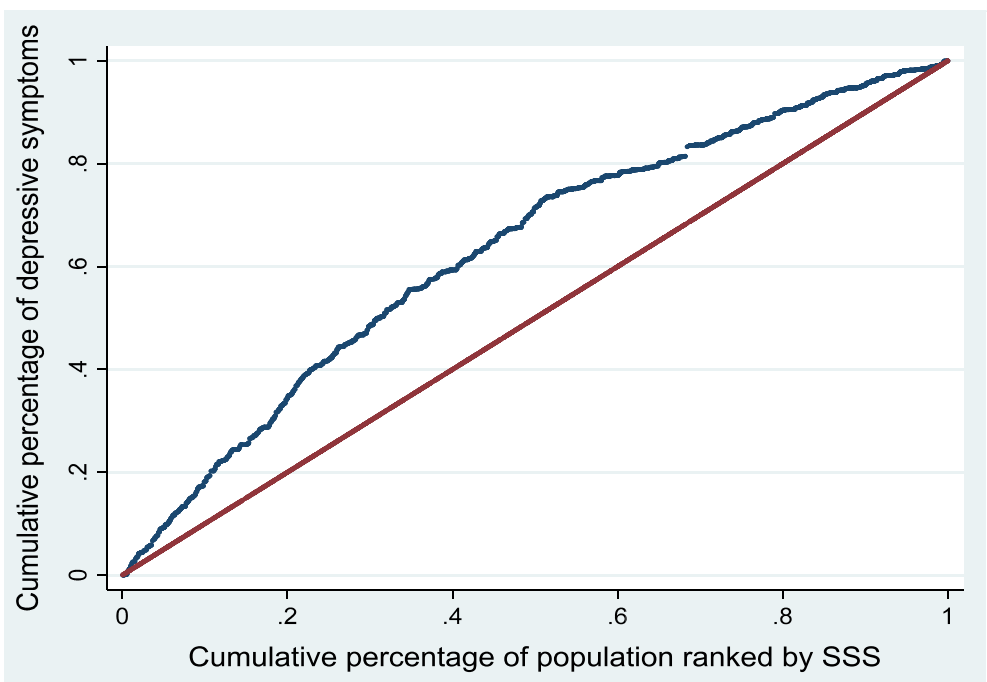

Fig. 2 Concentration curve for depressive symptoms - overall

\section{Discussion}

At $26 \%$, the overall prevalence of depressive symptoms is relatively high. This figure is comparable to the 2012 estimate of $27.1 \%$ from the National Income Dynamic Study (NIDS) that uses the CES-D 10's cut-off score of 10 [30]. The estimate also falls within the wide although not directly comparable range of prevalence rates reported in other CES-D 10-based studies using the nationally representative NIDS. Pengpid et al. for example reported a prevalence rate of 13\% for 2014/15 using a cut-off score of 12 [32], while Burns et al. reported a prevalence as high as $38.9 \%$ for 2008 using the cut-off score of 10 [31]. Similar to the significant gender difference reported here, other studies also found women to have an increased risk of depression [31, 33], higher CES-D 10 scores [30], and increased stress [34].

The one main objective of the paper was to quantify, using the CI, the extent of SSS-related inequality in depressive symptoms. Similar to evidence on self-reported health presented elsewhere [20, 21], the CIs for depressive symptoms in our study revealed an unequal distribution of depressive symptoms among South Africans. Our results likewise show significant SSS-related inequalities that favour those with higher SSS rank, with depressive status being concentrated in those of lower social status. Although our study makes use of SSS, our result is consistent with previous evidence from South Africa that used objective socio-economic status to measure inequalities in

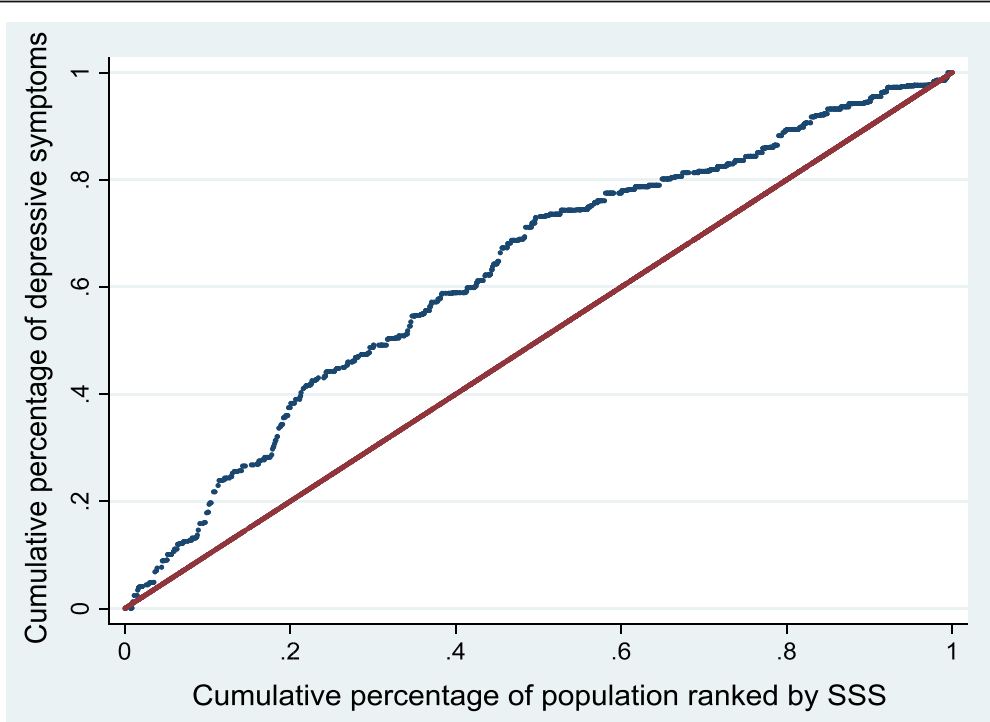

Fig. 3 Concentration curve for depressive symptoms - males 


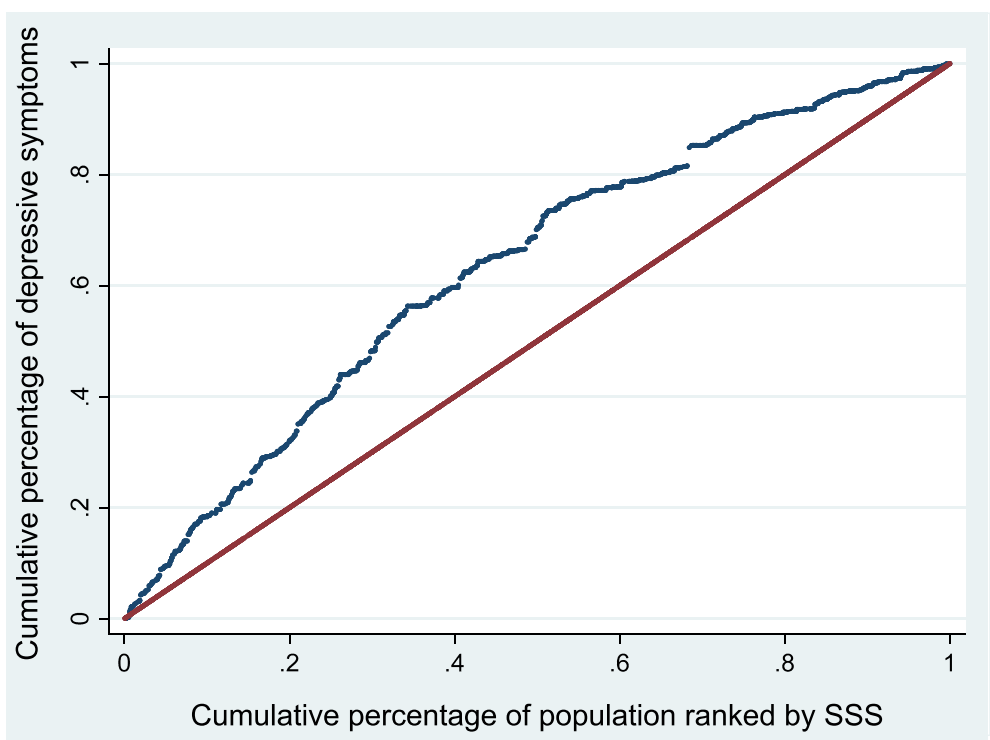

Fig. 4 Concentration curve for depressive symptoms - females

depression. These studies also report negative concentration indices, which shows disparities in depression that favour the better off [62,63]. Various authors have also shown that low socio-economic status is a risk factor for mental health illness such as depression [30-32, 34, 64, 65]. Our results are also consistent with other studies that make use of the CI to measure SSS inequalities and find inequalities in self-rated health that favour the top social classes [20, 21]. In fact, the extent of inequality is much more pronounced in this developing country context than that reported in the only other comparable study conducted in a developed country, namely Spain [20]. In this study, the reported concentration indices, though negative as well, are as low as -0.021 and -0.045 respectively for the two measures of self-reported health status. Consistent with other studies that also make use of the CES-D scale, we also find that the prevalence of depressive symptoms was higher in females when compared to males [30, 32].

Our paper also sought to examine the contribution of various factors to SSS-related inequalities in depressive symptoms both on aggregate and by gender. Using a decomposition approach, we find that SSS, race and past childhood adversity make important contributions to SSSrelated inequalities in depressive symptoms. Our results are in line with previous studies that found that SSS has a significant influence on depression [5, 12, 13, 15, 34, 50]. Using RII, studies by Adler at al. and Miyakawa et al. both show a significant relationship between depression and SSS $[12,13]$. Of note in this study was the difference in the contributions of SSS across gender. The contribution of SSS to inequalities in depressive symptoms was higher for women than men. This highlights the importance of considering the unique ways in which men and women conceptualise and evaluate their place in the social hierarchy when interpreting the impact of SSS on depression. As noted in Shaked et al., the factors that may be pertinent in predicting SSS for women differ to those for men [66] and thus the strengths of association would differ, as is the case in this particular study.

The contribution of the childhood adversity variable to SSS-related inequalities was also higher for females when compared to males. Other studies also point to the effect of childhood adversities on mental health [26, 54], with stronger associations being recorded for females when compared to males [67]. This may be attributable to the differences in the psychology of emotions in women versus men or the different influences of specific types of childhood adversities in women versus males. Findings from a study by Veijola et al. show that more childhood factors were associated with depression in females when compared to males [68].

Race was another variable that showed some influence on inequalities in depressive symptoms. The relationship in South Africa between race and the prevalence of illness related to depression has been documented before [30, 31, 65]. In South Africa, the race variable is intricately connected with social status, which varies due to the direct and indirect effects of the discriminatory socioeconomic policies under the apartheid system. This makes it difficult to separate the associations of race and depressive symptoms from the associations of SSS with depressive symptoms. The contribution of race to inequalities in the prevalence of depressive symptoms related to SSS also points to the importance of cultural differences in shaping the expression and experiences of depression [69]. Our study further shows that the contribution of race to SSS 


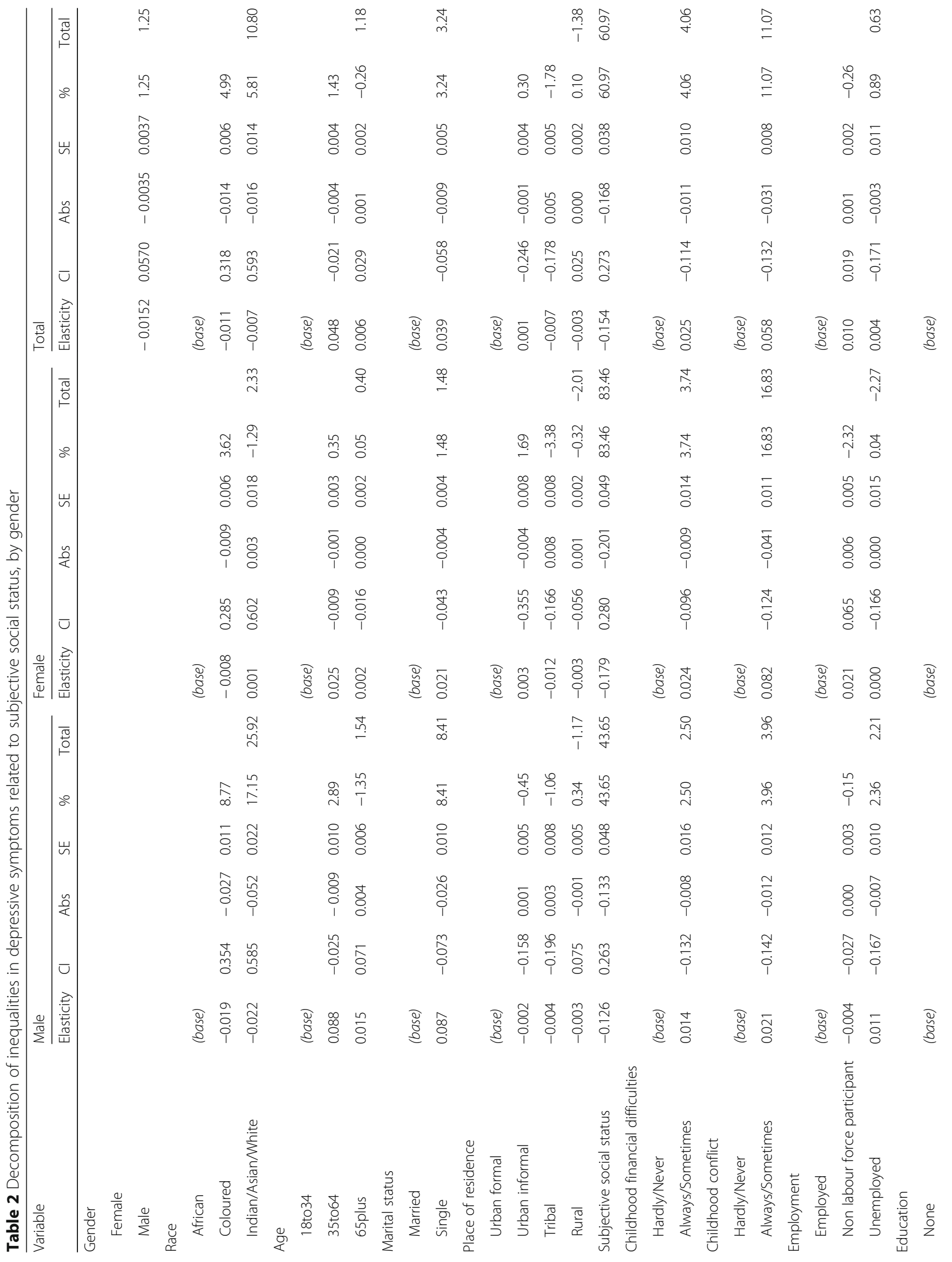


Mutyambizi et al. International Journal for Equity in Health $\quad$ (2019) 18:87

Page 10 of 13

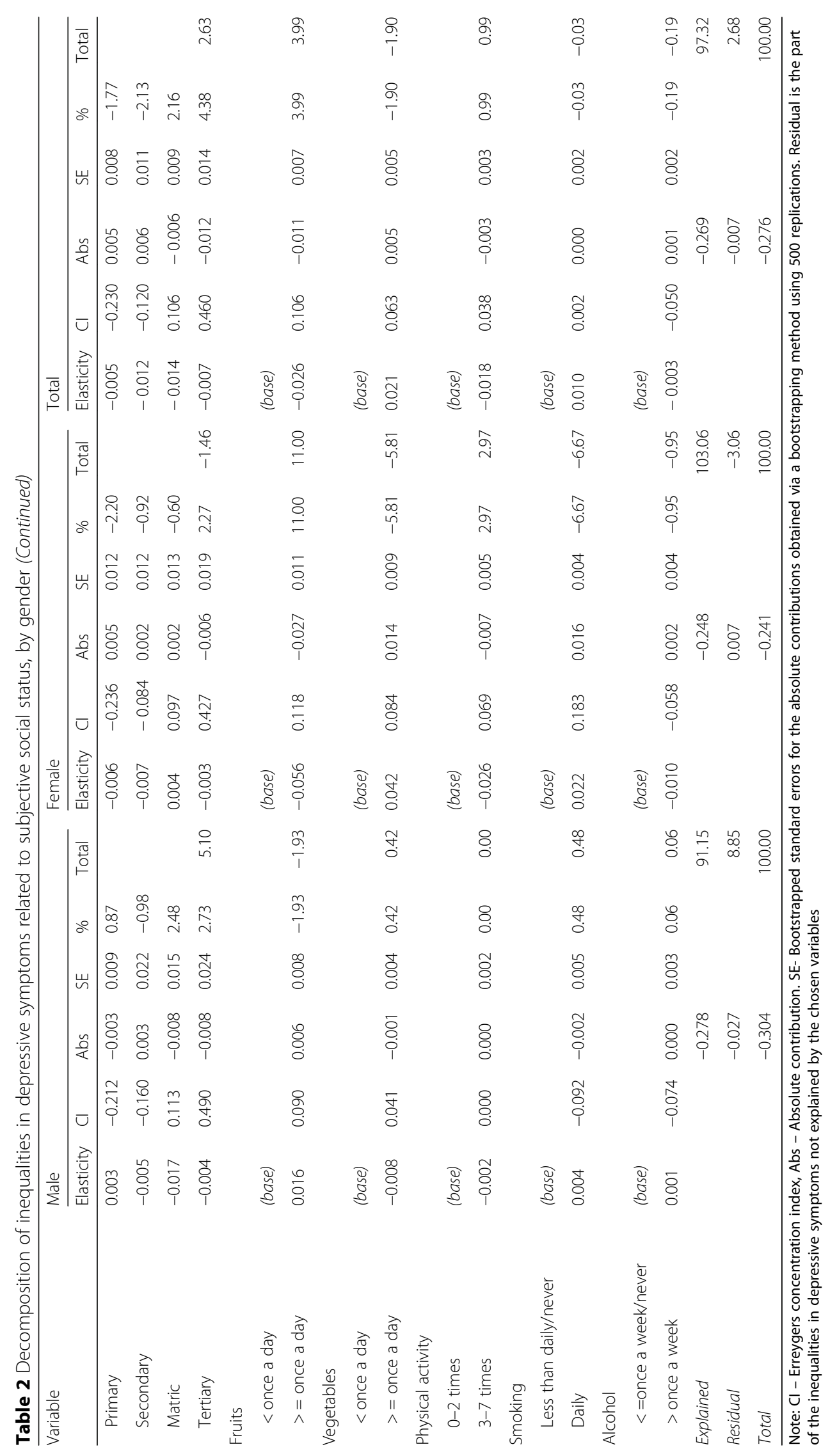


inequalities in depressive symptoms is higher amongst males when compared this females. Such differences in contribution may be due to the effect of race on inequalities in depressive symptoms amongst females being captured by other significant variables such as SSS.

This study has several limitations. Firstly, the use of a cross sectional dataset limits the discussion of causal relationships between SSS-related inequalities and its various determinants, with the result that evidence points to associations only. In future studies questions of causality may be addressed by use of longitudinal data. Secondly, the study uses a self-reported measure of depression, rather than clinical diagnosis, and also relies on self-report for the measurement of some covariates included in the analysis, which may introduce some subjectivity and bias into the results. This study, furthermore, employs a broad societal reference group in its operationalisation of the SSS construct. Using closer referents such as community members or similar others, which may be more appropriate in regards to mental health, may yield different results [70-72]. Further, our study does not present information on the distribution of depressive symptoms in subjects below the age of 18 years. Future studies that cover this age group could better represent the contribution of SSS to overall inequalities in depression. Despite these caveats this paper has a major strength. The study makes use of nationally representative data to estimate SSS-related inequalities in depressive symptoms among South African adults. The analytical strategy combines the rigour of the European Social Survey's approach to the study of the social determinants of health with information on subjective social status, which was not included in the standard ESS7 survey module.

\section{Conclusion}

The results of this study document the presence of much more significant SSS-related inequalities in depressive symptoms favouring those of higher social status when compared to developed countries. To the best of our knowledge, this is the first study of its kind to apply decomposition analysis to the investigation of SSS-related inequalities in health. The study shows that the observed SSS-related inequalities in depressive symptoms are mostly explained by SSS itself followed by race and past childhood conflict. The size of the contributions made by these factors differ by gender, highlighting the importance of gender-based analysis in studies of health inequalities. Results from this study suggest that policy makers seeking to reduce SSS-related inequalities in depression should target a reduction in the positive contribution of SSS to depression via the implementation of programmes that improve social welfare. Given the much greater contribution to inequalities among females, these policies should target women. Policies that protect children and especially the girl child from conflict can also be useful in reducing inequalities in depression related to subjective social status during adulthood. Overall, there is need for a multisectoral approach to address these inequalities.

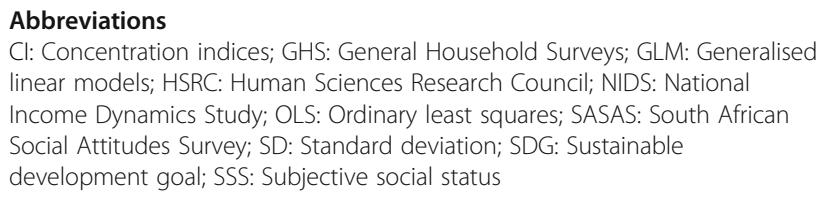
linear models; HSRC: Human Sciences Research Council; NIDS: National Income Dynamics Study; OLS: Ordinary least squares; SASAS: South African Social Attitudes Survey; SD: Standard deviation; SDG: Sustainable development goal; SSS: Subjective social status

\section{Acknowledgements}

Our gratitude goes to those who participated in the survey and those who funded the study.

\section{Authors' contributions}

All authors are responsible for the design of the work. CM performed the data analysis and drafted the manuscript. FB provided a critical review of the data analysis and manuscript. PS and TE provided a critical review of the manuscript. All authors read and approved the final manuscript.

\section{Funding}

SASAS 2014 was funded by the Human Sciences Research Council (HSRC) and the ESS module was funded by the Newton Fund (DFID/NRF).

Availability of data and materials

The dataset(s) used in this article is available on request from the HSRC.

Ethics approval and consent to participate

South African Social Attitudes Survey (SASAS) received ethical approval from the HSRC Research Ethics Committee (REC).

\section{Consent for publication}

Not applicable.

\section{Competing interests}

The authors declare that they have no competing interests.

\section{Author details}

${ }^{1}$ Research Use and Impact Assessment (RIA), Human Sciences Research Council (HSRC), HSRC Building, 134 Pretorius Street, Pretoria 0002, South Africa. ${ }^{2}$ School of Economic and Business Sciences (SEBS), University of the Witwatersrand (Wits), Johannesburg, South Africa. ${ }^{3}$ Centre for Global Health Inequalities Research (CHAIN), Department of Sociology and Political Science, Norwegian University of Science and Technology (NTNU), Trondheim, Norway.

Received: 23 November 2018 Accepted: 4 June 2019

Published online: 13 June 2019

\section{References}

1. Lorant $V$, Deliège $D$, Eaton W, Robert A, Philippot $P$, Ansseau M. Socioeconomic inequalities in depression: a meta-analysis. Am J Epidemiol. 2003;157(2):98-112.

2. Lund C, Breen A, Flisher AJ, Kakuma R, Corrigall J, Joska JA, et al. Poverty and common mental disorders in low and middle income countries: a systematic review. Soc Sci Med. 2010;71(3):517-28.

3. Reiss F. Socioeconomic inequalities and mental health problems in children and adolescents: a systematic review. Soc Sci Med. 2013;90:24-31.

4. Euteneuer F. Subjective social status and health. Curr Opin Psychiatr. 2014; 27(5):337-43.

5. Quon EC, McGrath JJ. Subjective socioeconomic status and adolescent health: a meta-analysis. Health Psychol. 2014;33(5):433.

6. Tang KL, Rashid R, Godley J, Ghali WA. Association between subjective social status and cardiovascular disease and cardiovascular risk factors: a systematic review and meta-analysis. BMJ Open. 2016;6(3):e010137.

7. Singh-Manoux A, Marmot MG, Adler NE. Does subjective social status predict health and change in health status better than objective status? Psychosom Med. 2005;67(6):855-61. 
8. Scott KM, Al-Hamzawi AO, Andrade LH, Borges G, Caldas-de-Almeida JM, Fiestas F, et al. Associations between subjective social status and DSM-IV mental disorders: results from the world mental health surveys. JAMA Psychiatry. 2014;71(12):1400-8.

9. Präg P, Mills MC, Wittek R. Subjective socioeconomic status and health in cross-national comparison. Soc Sci Med. 2016;149:84-92.

10. Franzini L, Fernandez-Esquer ME. The association of subjective social status and health in low-income Mexican-origin individuals in Texas. Soc Sci Med. 2006;63(3):788-804.

11. Singh-Manoux A, Adler NE, Marmot MG. Subjective social status: its determinants and its association with measures of ill-health in the Whitehall II study. Soc Sci Med. 2003;56(6):1321-33.

12. Adler N, Singh-Manoux A, Schwartz J, Stewart J, Matthews K, Marmot MG. Social status and health: a comparison of British civil servants in Whitehall-II with European-and African-Americans in CARDIA. Soc Sci Med. 2008;66(5):1034-45.

13. Miyakawa M, Magnusson Hanson LL, Theorell T, Westerlund H. Subjective social status: its determinants and association with health in the Swedish working population (the SLOSH study). Eur J Public Health. 2011;22(4):593-7.

14. Demakakos P, Nazroo J, Breeze E, Marmot M. Socioeconomic status and health: the role of subjective social status. Soc Sci Med. 2008;67(2):330-40.

15. Hoebel J, Maske UE, Zeeb H, Lampert T. Social inequalities and depressive symptoms in adults: the role of objective and subjective socioeconomic status. PLoS One. 2017;12(1):e0169764.

16. Ghaed SG, Gallo LC. Subjective social status, objective socioeconomic status, and cardiovascular risk in women. Health Psychol. 2007;26(6):668.

17. Sakurai K, Kawakami N, Yamaoka K, Ishikawa H, Hashimoto H. The impact of subjective and objective social status on psychological distress among men and women in Japan. Soc Sci Med. 2010;70(11):1832-9.

18. Karvonen S, Rahkonen O. Subjective social status and health in young people. Sociol Health IIIn. 2011;33(3):372-83.

19. Charonis A, Kyriopoulos H-I, Spanakis M, Zavras D, Athanasakis K, Pavi E, et al. Subjective social status, social network and health disparities: empirical evidence from Greece. Int J Equity Health. 2017;16(1):40.

20. Costa J, Garcia J. Measuring socioeconomic health inequalities: fiction or reality? Int J Soc Econ. 2003;30(8):883-92.

21. Elgar FJ, McKinnon B, Torsheim T, Schnohr CW, Mazur J, Cavallo F, et al. Patterns of socioeconomic inequality in adolescent health differ according to the measure of socioeconomic position. Soc Indic Res. 2016;127(3):1169-80

22. Seedat S, Scott KM, Angermeyer MC, Berglund P, Bromet EJ, Brugha TS, et al. Cross-national associations between gender and mental disorders in the World Health Organization world mental health surveys. Arch Gen Psychiatry. 2009;66(7):785-95.

23. Piccinelli M, Wilkinson $\mathrm{G}$. Gender differences in depression: critical review. $\mathrm{Br}$ J Psychiatry. 2000;177(6):486-92.

24. Abate $\mathrm{KH}$. Gender disparity in prevalence of depression among patient population: a systematic review. Ethiop J Health Sci. 2013;23(3):283-8.

25. Gahagan J, Gray K, Whynacht A. Sex and gender matter in health research: addressing health inequities in health research reporting. Int J Equity Health. 2015;14(1):12.

26. Hughes K, Bellis MA, Hardcastle KA, Sethi D, Butchart A, Mikton C, et al. The effect of multiple adverse childhood experiences on health: a systematic review and meta-analysis. Lancet Public Health. 2017;2(8):e356-e66.

27. Eikemo TA, Bambra C, Huijts T, Fitzgerald R. The first pan-European sociological health inequalities survey of the general population: the European social survey rotating module on the social determinants of health. Eur Sociol Rev. 2017;33(1):137-53.

28. Herman AA, Stein DJ, Seedat S, Heeringa SG, Moomal H, Williams DR. The south African stress and health (SASH) study: 12-month and lifetime prevalence of common mental disorders. S Afr Med J. 2009;(5):99.

29. Williams D, Herman A, Stein D, Heeringa S, Jackson P, Moomal H, et al. Twelve-month mental disorders in South Africa: prevalence, service use and demographic correlates in the population-based south African stress and health study. Psychol Med. 2008;38(2):211-20.

30. Adjaye-Gbewonyo K, Avendano M, Subramanian S, Kawachi I. Income inequality and depressive symptoms in South Africa: a longitudinal analysis of the National Income Dynamics Study. Health Place. 2016;42:37-46.

31. Burns JK, Tomita A, Lund C. Income inequality widens the existing incomerelated disparity in depression risk in post-apartheid South Africa: evidence from a nationally representative panel study. Health Place. 2017;45:10-6.
32. Pengpid S, Peltzer K. Depression symptoms: their association with sociodemographic factors and health among adults in South Africa. J Psychol Afr. 2018;28(1):62-5.

33. Tomlinson M, Grimsrud AT, Stein DJ, Williams DR, Myer L. The epidemiology of major depression in South Africa: results from the south African stress and health study. S Afr Med J. 2009;(5):99, 367-373.

34. Hamad R, Fernald L, Karlan D, Zinman J. Social and economic correlates of depressive symptoms and perceived stress in south African adults. J Epidemiol Community Health. 2008;62(6):538-44.

35. Institute for Health Metrics and Evaluation (IHME). 2017 global burden of disease. Country profile: South Africa 2018 [20 November 2018]. Available from: http://www.healthdata.org/south-africa.

36. Sulla V, Zikhali P. In: Washington, DC, editor. Overcoming poverty and inequality in South Africa: An assessment of drivers, constraints and opportunities: the World Bank Group retrieved on July, 25th; 2018.

37. United Nations. Transforming our world: the 2030 agenda for sustainable development a/RES/70/1. New York: United Nations; 2015.

38. Balaj M, McNamara CL, Eikemo TA, Bambra C. The social determinants of inequalities in self-reported health in Europe: findings from the European social survey (2014) special module on the social determinants of health. Eur J Pub Health. 2017;27(suppl_1):107-14.

39. McNamara CL, Balaj M, Thomson KH, Eikemo TA, Solheim EF, Bambra C. The socioeconomic distribution of non-communicable diseases in Europe: findings from the European social survey (2014) special module on the social determinants of health. Eur J Public Health. 2017;27(suppl_1):22-6.

40. Thomson KH, Renneberg A-C, McNamara CL, Akhter N, Reibling N, Bambra C. Regional inequalities in self-reported conditions and non-communicable diseases in European countries: findings from the European social survey (2014) special module on the social determinants of health. Eur J Public Health. 2017;27(suppl_1):14-21.

41. Huijts T, Stornes P, Eikemo TA, Bambra C, Consortium H. Prevalence of physical and mental non-communicable diseases in Europe. Findings from the European social survey (2014) special module on the social determinants of health. Eur J Public Health. 2017;27(suppl_1):8-13.

42. Bøe T, Balaj M, Eikemo TA, McNamara CL, Solheim EF. Financial difficulties in childhood and adult depression in Europe. Eur J Public Health. 2017; 27(suppl_1):96-101.

43. Reibling N, Beckfield J, Huijts T, Schmidt-Catran A, Thomson KH, Wendt C. Depressed during the depression: has the economic crisis affected mental health inequalities in Europe? Findings from the European social survey (2014) special module on the determinants of health. Eur J Public Health. 2017;27(suppl_1):47-54.

44. Human Sciences Research Council. SASAS 2014 Data Description Form; 2014. Available from: http://www.europeansocialsurvey.org/data/related_ studies/SASAS_2014.html. Accessed 3 Apr 2018.

45. Vilagut $G$, Forero CG, Barbaglia G, Alonso J. Screening for depression in the general population with the center for epidemiologic studies depression (CES-D): a systematic review with meta-analysis. PLoS One. 2016;11(5):e0155431.

46. Karim J, Weisz R, Bibi Z, ur Rehman S. Validation of the eight-item center for epidemiologic studies depression scale (CES-D) among older adults. Curr Psychol. 2015;34(4):681-92.

47. O'Halloran A, Kenny R, King-Kallimanis B. The latent factors of depression from the short forms of the CES-D are consistent, reliable and valid in community-living older adults. Eur Geriatr Med. 2014;5(2):97-102.

48. von dem Knesebeck O, Pattyn E, Bracke P. Education and depressive symptoms in 22 European countries. Int J Public Health. 2011;56(1):107-10.

49. Cundiff JM, Smith TW, Uchino BN, Berg CA. Subjective social status: construct validity and associations with psychosocial vulnerability and selfrated health. Int J Behav Med. 2013;20(1):148-58.

50. McLaughlin KA, Costello EJ, Leblanc W, Sampson NA, Kessler RC. Socioeconomic status and adolescent mental disorders. Am J Public Health. 2012;102(9):1742-50

51. Krieger N. Genders, sexes, and health: what are the connections-and why does it matter? Int J Epidemiol. 2003;32(4):652-7.

52. Solar O, Irwin A. A conceptual framework for action on the social determinants of health; 2010.

53. World Health Organization and Calouste Gulbenkian Foundation. Social determinants of mental health. Geneva: World Health Organization; 2014.

54. Allen J, Balfour R, Bell R, Marmot M. Social determinants of mental health. Int Rev Psychiatr. 2014;26(4):392-407. 
55. Rahe $\mathrm{C}$, Unrath $\mathrm{M}$, Berger K. Dietary patterns and the risk of depression in adults: a systematic review of observational studies. Eur J Nutr. 2014; 53(4):997-1013.

56. Wagstaff A, Paci P, Van Doorslaer E. On the measurement of inequalities in health. Soc Sci Med. 1991;33(5):545-57.

57. O'Donnell O, Van Doorslaer E, Wagstaff A, Lindelow M. Analyzing health equity using household survey data: a guide to techniques and their implementation: World Bank Publications; 2008.

58. Erreygers G. Correcting the concentration index. J Health Econ. 2009; 28(2):504-15.

59. O'Donnell O, O'Neill S, Van Ourti T, Walsh B. Conindex: estimation of concentration indices. Stata J. 2016;16(1):112

60. Wagstaff A, Van Doorslaer E, Watanabe N. On decomposing the causes of health sector inequalities with an application to malnutrition inequalities in Vietnam. J Econ. 2003:112(1):207-23.

61. Yiengprugsawan V, Lim LL, Carmichael GA, Dear KB, Sleigh AC. Decomposing socioeconomic inequality for binary health outcomes: an improved estimation that does not vary by choice of reference group. BMC Res Notes. 2010;3(1):57.

62. Mukong AK, Van Walbeek C, Ross H. Lifestyle and income-related inequality in health in South Africa. Int J Equity Health. 2017;16(1):103.

63. Ataguba JE, Akazili J, McIntyre D. Socioeconomic-related health inequality in South Africa: evidence from general household surveys. Int J Equity Health. 2011;10(1):48.

64. Myer L, Stein DJ, Grimsrud A, Seedat S, Williams DR. Social determinants of psychological distress in a nationally-representative sample of south African adults. Soc Sci Med. 2008;66(8):1828-40.

65. Das-Munshi J, Lund C, Mathews C, Clark C, Rothon C, Stansfeld S. Mental health inequalities in adolescents growing up in post-apartheid South Africa: cross-sectional survey, SHaW study. PLoS One. 2016;11(5):e0154478.

66. Shaked D, Williams M, Evans MK, Zonderman AB. Indicators of subjective social status: differential associations across race and sex. SSM Popul Health. 2016:2:700-7.

67. Pirkola S, Isometsä E, Aro H, Kestilä L, Hämäläinen J, Veijola J, et al. Childhood adversities as risk factors for adult mental disorders. Soc Psychiatry Psychiatr Epidemiol. 2005;40(10):769-77.

68. Veijola J, Puukka P, Lehtinen V, Moring J, Lindholm T, Väisänen E. Sex differences in the association between childhood experiences and adult depression. Psychol Med. 1998;28(1):21-7.

69. Office of the Surgeon General [US], Center for Mental Health Services [US] Culture counts: The influence of culture and society on mental health: Department of Health and Human Services, US Public Health Service; 2001. Report No:: 0160508924

70. Callan MJ, Kim H, Matthews WJ. Predicting self-rated mental and physical health: the contributions of subjective socioeconomic status and personal relative deprivation. Front Psychol. 2015;6:1415.

71. Wolff LS, Acevedo-Garcia D, Subramanian S, Weber D, Kawachi I. Subjective social status, a new measure in health disparities research: do race/ethnicity and choice of referent group matter? J Health Psychol. 2010;15(4):560-74.

72. Wolff LS, Subramanian S, Acevedo-Garcia D, Weber D, Kawachi I. Compared to whom? Subjective social status, self-rated health, and referent group sensitivity in a diverse US sample. Soc Sci Med. 2010;70(12):2019-28.

\section{Publisher's Note}

Springer Nature remains neutral with regard to jurisdictional claims in published maps and institutional affiliations.

Ready to submit your research? Choose BMC and benefit from:

- fast, convenient online submission

- thorough peer review by experienced researchers in your field

- rapid publication on acceptance

- support for research data, including large and complex data types

- gold Open Access which fosters wider collaboration and increased citations

- maximum visibility for your research: over $100 \mathrm{M}$ website views per year

At $\mathrm{BMC}$, research is always in progress.

Learn more biomedcentral.com/submissions 